\title{
AQUARELAS ORIGINAIS DE JOÃO BARBOSA RODRIGUES NA REGIÃO AMAZÔNICA: OS CAMINHOS PERCORRIDOS ATÉ O RETORNO AO JARDIM BOTÂNICO DO RIO DE JANEIRO
}

\author{
ORIGINAL WATERCOLORS BY JOÃO BARBOSA RODRIGUES IN THE \\ AMAZON REGION: THE PATHS TAKEN UNTIL THE RETURN TO THE \\ BOTANICAL GARDEN OF RIO DE JANEIRO
}

Lin Chau MING

Programa de Pós-Graduação em Agroecossistemas - Centro de Ciências Agrárias, Universidade Federal de Santa Catarina - Florianópolis - SC. e-mail: linming2809@gmail.com

\section{RESUMO}

Neste trabalho são relatados os caminhos que percorreram nove aquarelas originais de João Barbosa Rodrigues, produzidas na Amazônia entre 1823 a 1825, passando pela cidade de Nova York/USA, até o retorno ao Jardim Botânico do Rio de Janeiro/Brasil, do qual foi diretor entre 1890-1909. Barbosa Rodrigues é considerado um dos principais botânicos da flora amazônica numa época em que pouco se estudava a região e seus trabalhos mostram, além de aspectos botânicos das plantas estudadas, sua habilidade em desenhos bem detalhados e seu interesse na inclusão de populações nos locais por onde transitou. São apresentados detalhes pessoais e familiares de alguns de seus descendentes e como isso facilitou esse processo de retorno das obras, além de mostrar uma descrição das aquarelas.

Palavras-chave: Desenhos históricos, Brasil Colonial, etnografia, etnobotânica histórica

\begin{abstract}
This work reports the paths taken by nine original watercolors by João Barbosa Rodrigues, produced in the Amazon between 1823 and 1825, passing through New York City/USA, until their return to the Botanical Garden of Rio de Janeiro/Brazil, of which he was director from 1890 to 1909. Barbosa Rodrigues is considered one of the main botanists of the Amazonian flora at a time when little was studied in the region and his works show, in addition to botanical aspects of the plants studied, his ability in very detailed drawings and his interest in including populations in the places where he transited. Personal and family details of some of their descendants are presented and how this facilitated this process of returning the works and a description of the watercolors is shown.
\end{abstract}

Keywords: Historical drawings, Colonial Brazil, ethnography, historical ethnobotany

\section{INTRODUÇÃO}

João Barbosa Rodrigues foi um importante botânico brasileiro em meados do século XIX e início do século XX. Escreveu diferentes obras sobre plantas brasileiras (Rodrigues, 1983), em especial sobre orquídeas (Rodrigues, 1877) e palmeiras (Rodrigues, 1903) e foi um dos fundadores da Arqueologia brasileira na Amazônia (Ferreira e Noelli, 2009). Dirigiu o Museu Botânico do Amazonas no período de 1882 a 1890 e também o Jardim Botânico do Rio de Janeiro de 1890 até sua morte, em 1909, tendo realizado, em ambos os locais, uma administração bastante produtiva, mesmo com a falta de recursos para ambas as instituições (Porto, 1891; Ihering, 1911).

Eclético, o naturalista transitou por diferentes áreas da Ciência, e fez de sua habilidade em desenho (foi professor dessa matéria no Colégio Pedro II, no Rio de Janeiro) uma importante ferramenta para a validação de seu trabalho (Sá, 2001; Peixoto et al., 2012); também como prova de que esteve nos locais citados e, em muitos deles, representava os membros das comunidades desses locais, o que não era usual na época (Instituto de Pesquisas Jardim Botânico do Rio de Janeiro, 2020).

Ele teve muitos descendentes, tendo sua terceira esposa, Constança, dado à luz 12 filhos. Várias de suas cartas trocadas com naturalistas e políticos de sua época estavam em caixas que foram herdadas por alguns de seus descendentes, geração após geração, que incluíam também desenhos originais. Por circunstâncias diversas, estas caixas foram se perdendo, mas alguns dos desenhos foram preservados 
por Flora Castaño Ferreira, bisneta do botânico, que publicou um artigo em parceria com Scott Mori, do Jardim Botânico de Nova York, quando ela morou naquela cidade (Mori e Ferreira, 1987), mostrando alguns desses desenhos. Após sua morte, os desenhos ficaram ao encargo de seu filho João Paulo Castaño Ferreira, que morava naquela mesma cidade.

$\mathrm{O}$ presente trabalho mostra parte da trajetória desses desenhos originais, a partir da passagem do autor pela cidade de Nova York e o encontro com um dos descendentes de João Barbosa Rodrigues, detentor dos desenhos, até a entrega deles, em doação, para o Jardim Botânico do Rio de Janeiro.

\section{Como foram obtidos os desenhos originais}

Nunca é demais dizer que coincidências acontecem na vida de modo inesperado. Fruto do acaso para muitos, desígnio de um ente superior para outros. Independentemente do que seja, o fato é que elas acontecem. O ano era de 2007, quando fui realizar pós-doutorado nos Estados Unidos, no Center for Environmental Research and Conservation (CERC), da Columbia University, em Nova York (Figura 1), com bolsas da FAPESP e do CNPq, em sequência, por dois anos.

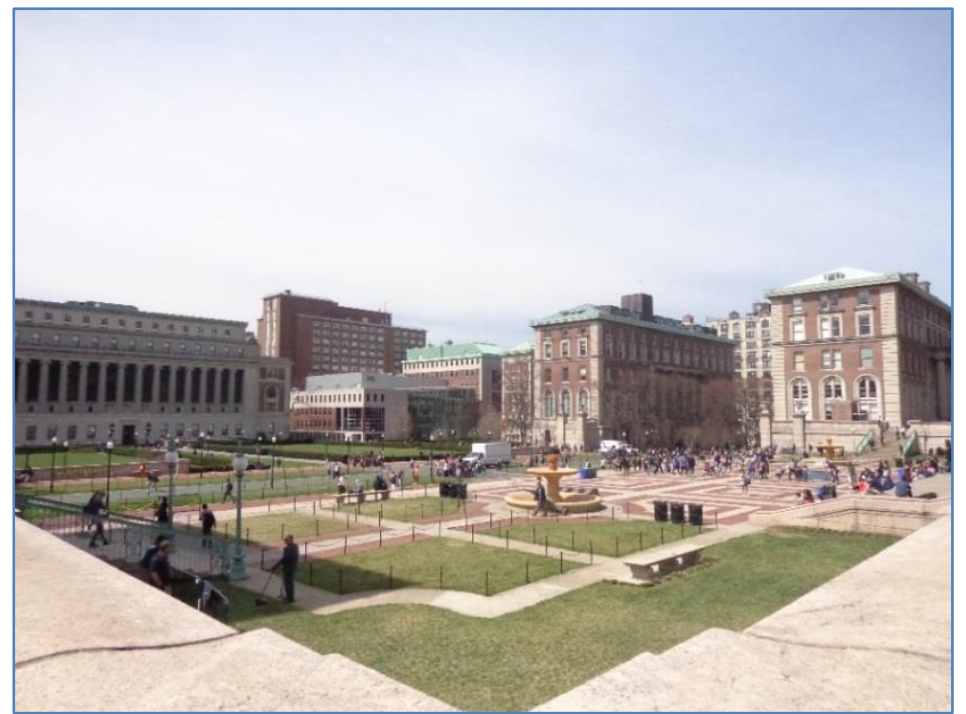

Figura 1. Campus da Columbia University em Nova York, Estados Unidos.

As duas primeiras semanas foram dedicadas à procura de apartamento para alugar e para fazer as matrículas de meus filhos em escolas públicas, além de me acostumar com o frio invernal, mês de fevereiro que era. Meu supervisor da época, Professor Miguel Pinedo-Vasquez, daquela universidade americana, ofereceu-nos seu apartamento em Manhattan, pois estaria viajando, enquanto não achássemos um local para morar, o que foi prontamente aceito.

O bairro onde a Columbia se localiza é proibitivo para um professor universitário brasileiro que queira morar em suas redondezas, pois a bolsa brasileira oferecida não cobre os valores médios dos aluguéis. Então a solução foi morar em locais mais distantes e baratos, mas aumentando o tempo de deslocamento para o trabalho, como a maior parte dos trabalhadores faz em qualquer lugar do mundo.

Após encontrar um apartamento no bairro do Harlem, famoso em épocas passadas por ser reduto de comunidades afrodescendentes e depois decadente, mas hoje em processo de revitalização, nos instalamos e passei a reorganizar a vida familiar e profissional a partir disso, que seria muito diferente da que estava acostumado em Botucatu, no Brasil.

Financeiramente, tinha que me organizar com o valor da bolsa recebida, de US\$2.100. Os períodos de pós-doutorado no exterior servem como momentos de aprendizagens e trocas de experiências para nós pesquisadores, sendo a bolsa oferecida uma ajuda muitíssimo importante para auxiliar nas despesas, as quais de modo geral são bastante altas.

Esta bolsa foi particularmente crucial porque meu salário estava todo comprometido com um investimento que estava fazendo na época (havia comprado uma casa de um colega da faculdade, dividido em 24 meses), então teríamos que nos virar com o valor da bolsa. Naquela época o valor da bolsa não incluía um adicional de "cidade cara", como Nova York e outras de uma listagem feita posteriormente pelo $\mathrm{CNPq}$, que também depois reajustou um pouco o valor da bolsa. 
E qual o valor do aluguel do apartamento no Harlem? US\$1.700. Ou seja, teríamos apenas US\$ 400 para todas as outras despesas de manutenção familiar na Big Apple, o que, evidentemente, era insuficiente. Somente o valor do metrô, num cartão mensal para uso ilimitado, era de US\$ 106 por pessoa, fora as despesas de alimentação, luz, gás, roupas, higiene pessoal etc. Daí a necessidade de arrumarmos recursos extras.

Consegui fazer bicos noturnos em restaurante como lavador de pratos ou como faxineiro nos finais de semana em condomínios nos arredores da cidade, o que aliviou um pouco a situação, mas que tirava também um pouco do foco que eu teria do meu pós-doutorado, e então minha esposa também decidiu (ou foi levada a isso) trabalhar como faxineira, uma das opções mais comuns para os imigrantes latinos (e de outros países) nos Estados Unidos.

Decisão tomada, ela foi à busca do trabalho. Bastante difícil para ela, visto não conhecer muitas pessoas na cidade e não ter o inglês fluente. Buscou por anúncios de jornais e contatos com as poucas pessoas (brasileiras) que conheceu. Tudo em vão.

Num certo dia, levando meu filho Leonardo para ajudá-la, vão ao centro da cidade verificar algumas possibilidades. Seguem em direção à estação 145th Street do metrô da linha 3 para downtown. Passam a catraca e ao descerem as escadarias ouvem o sinal sonoro do trem que estava para partir. Saem correndo, percorrem rapidamente um trecho da plataforma e conseguem adentrar no trem no último segundo. O trem não estava tão cheio e sentam num banco meio vazio. Cansados pelo esforço de última hora, descansam um pouco, ofegantes. Fôlego recomposto, passam a conversar sobre a cidade. Nisso, uma mulher que estava no banco em frente, interrompe-os, em português:

\section{- De onde são do Brasil?}

Migrante de Governador Valadares/MG, Graça, uma senhora já nos seus pouco mais de 50 anos, estava em Nova York há mais de 30 anos. Separada, com dois filhos menores na época, decidiu tentar vida nova na terra do Tio Sam. Trabalha desde que chegou como faxineira e conseguiu criar os filhos decentemente, com algum esforço. Apesar do tempo aqui, não tem fluência na língua inglesa e nem consegue escrever muito bem, mas se vira na conversação cotidiana com os patrões e coisas mais corriqueiras da vida neste país.

Diz sempre ajudar algum brasileiro que conhece pela cidade. E não foi o contrário com Margarete. Ofereceu dois serviços semanais para ela, de faxina também, proposta aceita sem pestanejar. Pensava em ir diminuindo o ritmo de trabalho, pois pensava em voltar ao Brasil em poucos anos e queria estar bem de saúde; dinheiro já tinha poupado um pouco, o suficiente para ter comprado uma casa em sua cidade natal.

Além disso, falou da existência de uma comunidade de brasileiros na cidade, com encontros dominicais em uma igreja católica no sul da ilha. Minha esposa, que é católica, ficou ainda mais contente. Despediram-se logo depois, não sem antes terem trocado os respectivos números de seus aparelhos celulares.

Assim foi o contato com a comunidade católica dos brasileiros em Manhattan. Não era o único grupo, soubemos de outros depois, mas com este, nos domingos subsequentes em que participávamos dos encontros, as afinidades e amizades foram aumentando, fazendo-nos continuar indo a esse grupo.

Depois de algum tempo, Margarete consegue preencher seu "schedule" semanal de trabalho de faxina, com várias casas a serem limpas, obtendo um ganho mensal aproximado de US\$2.000, resolvendo nossa situação financeira e me permitindo dedicar integralmente ao trabalho na Columbia.

A igreja "Our Lady of Pompei" (Nossa Senhora da Pompeia), localizada em South Village, em Manhattan (Figura 2) é uma obra feita pela comunidade italiana em meados de 1920 (Our Lady of Pompeii Church, 2002). Possui afrescos, vitrôs e estatuários que adornam a nave da igreja, muitos deles com aspectos históricos importantes (Guerra, 2011), relatados por Gutemberg Guerra, professor da 
Universidade Federal do Pará, em Belém, que realizou seu pós-doutorado na mesma época, também na Universidade de Columbia, no Centro de Estudos Latino-Americanos.

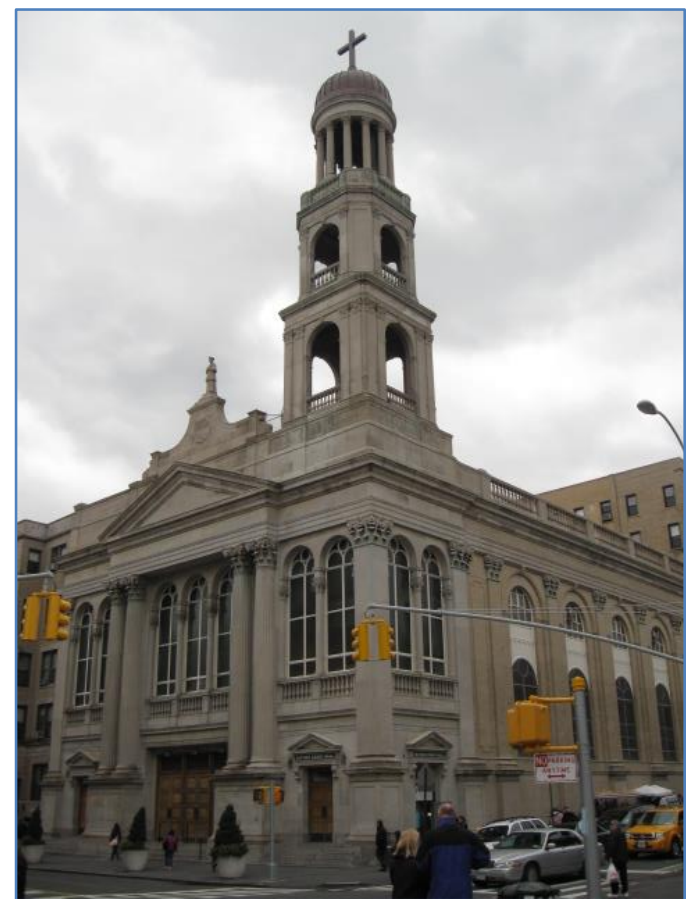

Figura 2. Igreja Nossa Senhora da Pompeia.

Coordenados por padres Scalabrinianos, tem missas aos domingos para comunidades americana, filipina e brasileira (Figura 3), estas últimas realizadas por religiosos brasileiros ou estrangeiros que falam o português com fluência, como o padre Vincenzo, italiano que nunca esteve no Brasil, mas falava um português irretocável, aprendido mediante estudos e convívio com os brasileiros em Nova York.

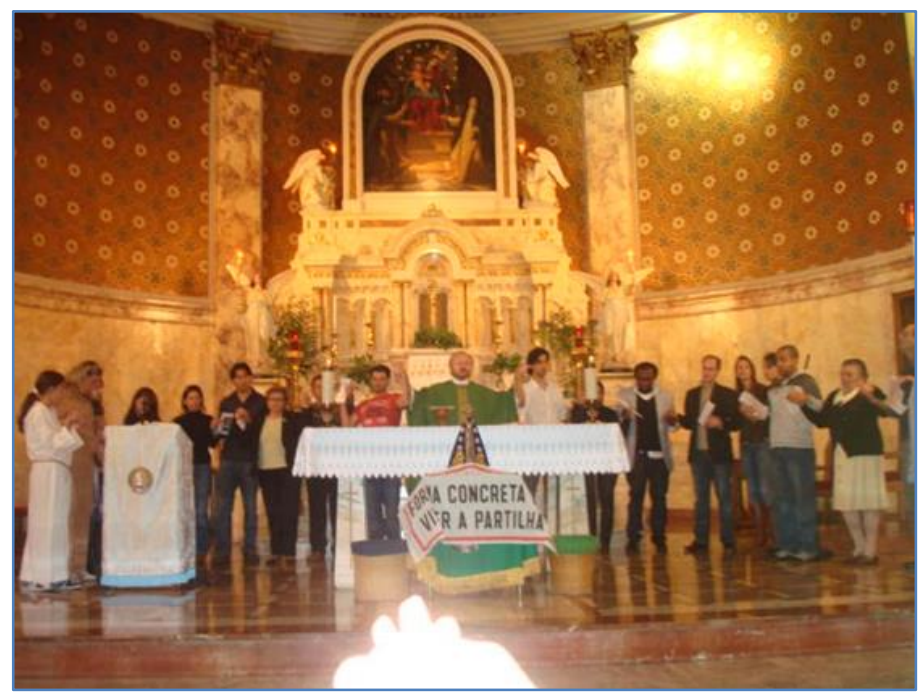

Figura 3. Missa da comunidade católica brasileira em Nova York.

E sempre após a missa a comunidade se reunia para um cafezinho, ou seja, uma reunião social informal, para conversas em português, trocar experiências e reforçar amizades, e apoiar pessoas que estão fora de seu país de origem. Foram semanas a fio, durante quase todo o período em Nova York, participando dessas reuniões, conversas e outras atividades que eram realizadas pelo grupo. Nossos domingos eram dedicados a isso. 
E nesse grupo se encontrava João Paulo Castaño-Ferreira, participante ativo da comunidade, ajudando os religiosos em seus afazeres e também organizando as atividades sociais (Figura 4). Churrascos ao ar livre e passeios pelo parque no verão, festas juninas, festa de ano novo, festa para os aniversariantes do mês e outras efemérides eram realizadas com sua ajuda. Carioca, era muito querido e respeitado por todos. Convidava também o pessoal para almoços ou jantares em seu pequeno apartamento no Bronx. Fomos a alguns deles

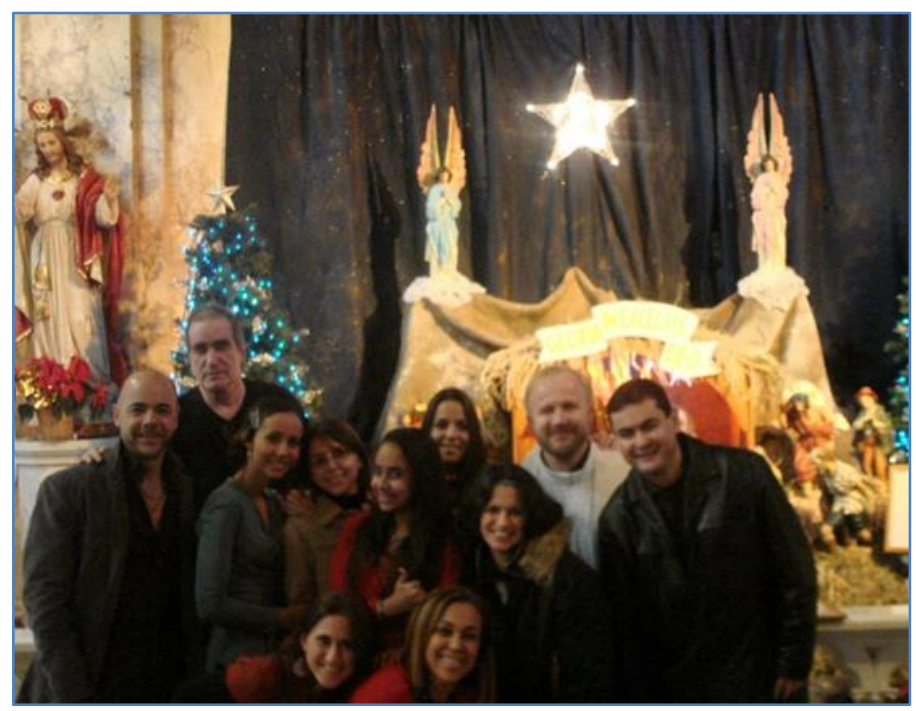

Figura 4. João Paulo Castaño Ferreira ao alto, à esquerda da foto.

O apartamento possuía apenas um quarto e a sala era em nível mais rebaixado, com assoalho de carvalho, havendo dois degraus de diferença com relação ao piso das outras partes do apartamento. Um sofá antigo e uma esteira elétrica mais moderna faziam o contraste mútuo. Em frente ao hall de entrada do quarto havia um corredor estreito, iluminado por uma única lâmpada no teto de estuque, como eram comuns nas construções anteriores à Segunda Guerra Mundial, com os tijolos à vista nas paredes exteriores do prédio, bem como as indefectíveis escadas metálicas contra incêndio também na parte de fora, iguais ao prédio dele.

$\mathrm{Na}$ sala e nesse corredor, pequenos quadros emoldurados com motivos diversos adornavam o ambiente, junto com outros desenhos, desta vez sem moldura. Acompanhando o corredor, estantes baixas de madeira envernizada estavam lotadas de livros, em sua maioria de arte e cultura brasileira, e havia também de plantas, muitos livros.

Observando os quadros e desenhos, vi alguns que representavam motivos indígenas, como machadinhos de pedra, potes de barro, muiraquitãs, e outro que mostrava indígenas com pinturas corporais, remetendo-me para a Amazônia. Fiquei curioso: como ele havia conseguido esses trabalhos originais?

Foi nesse momento que soube que João Paulo era tataraneto do famoso botânico João Barbosa Rodrigues, diretor do Jardim Botânico do Rio de Janeiro, num período entre o final do Império e início da República. E ele me contou um pouco de sua história e de como esses desenhos, que eram nove, vieram parar em Nova York.

João Paulo era filho de Flora Campos e Antônio Castaño-Ferreira. Sua mãe era filha de Paulo Campos Porto e Antonieta Franco de Campos Porto. Paulo Porto havia sido diretor do Jardim Botânico também. Flora era ainda neta de Joaquim Campos Porto e Maria Barbosa Rodrigues (pais de Paulo Porto) e bisneta de João Barbosa Rodrigues e Constança Barbosa Rodrigues (Sá, 2001).

Sua mãe, Flora, nasceu em 1917 e foi casada com Antônio Castaño-Ferreira. Viúva, casou-se com Henry Potter Lage, americano filho de brasileiro (Frederico Lage) e foi morar em Nova York em 1987, enviuvando novamente em 1992. Faleceu em 2003.

Era uma artista plástica habilidosa, tendo produzido muitos desenhos; também dirigiu peças teatrais e organizou eventos de artes com marionetes que produzia. Dirigiu curta metragem ("Êle e o Rabisco" - 1966) (Cinemateca Brasileira, 2020), onde também seus bonecos de marionete foram utilizados. Gostava muito de arte popular e era uma estudiosa desses movimentos artísticos. 
Seu gosto pelas artes era complementado pelo gosto pela Botânica. Livros com desenhos de plantas ajudavam em sua imaginação criativa. Fez algumas pinturas com motivos vegetais. E sobre os desenhos de seu bisavô, escreveu artigo publicado em 1987 na revista do Jardim Botânico de Nova York (Brittonia) (Figura 5), em conjunto com Scott Mori, botânico daquele Jardim Botânico, especialista em Lecythidaceae e grande experiência na Amazônia, onde apresentou alguns dos desenhos - inéditos -, feitos por ele em sua viagem pela Amazônia (Mori e Castaño-Ferreira, 1987) (Figura 6).

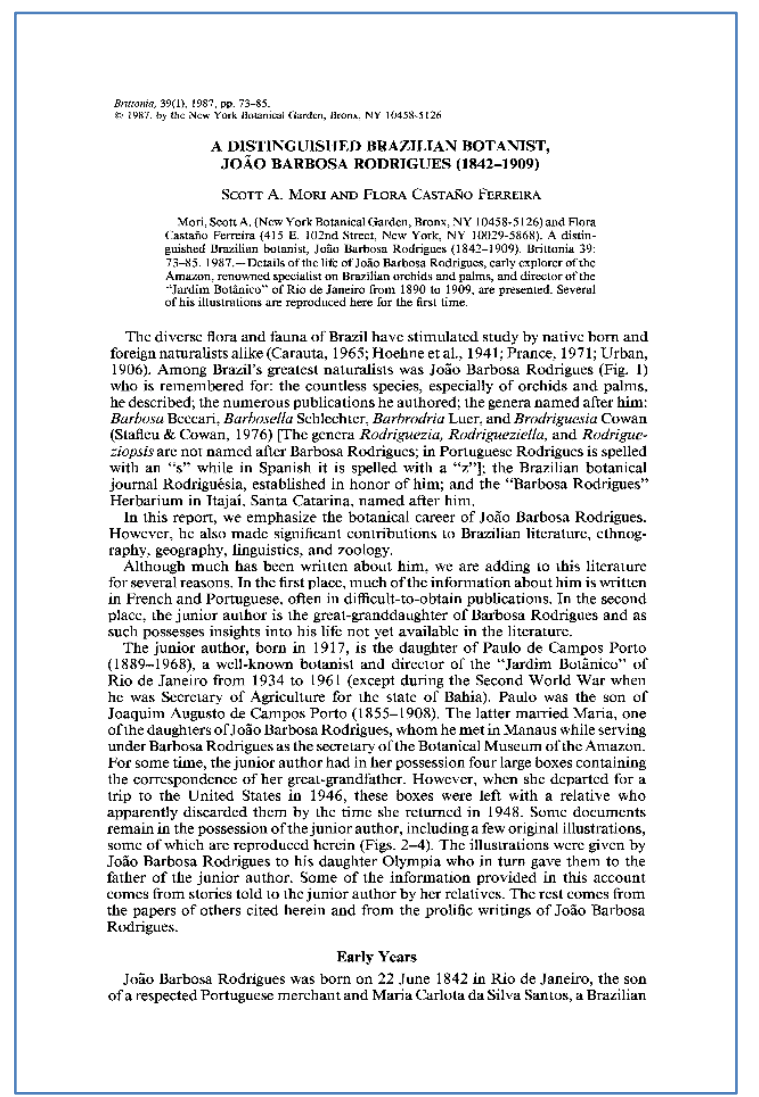

Figura 5. Fac-símile do artigo publicado na revista Brittonia.

Assim, por anos, esses desenhos permaneceram desconhecidos pelo mundo acadêmico até a publicação desse artigo. E os seus originais permaneceram expostos nas paredes do apartamento em Nova York de seu tataraneto, disponível apenas para aqueles que lá fossem visitar seu representante familiar na atualidade, mesmo que talvez nem soubessem da origem ou importância desses trabalhos.

- Por que você não doa esses desenhos para alguma instituição no Rio de Janeiro? perguntei, tentando dar um destino mais adequado e útil para aquelas obras históricas.

- Lin, sou carioca e sei como são as coisas no Rio de Janeiro. As instituições estão sucateadas, quase falidas, muita coisa abandonada, goteiras por toda a parte, fiação elétrica exposta (como se fizesse um prenúncio do que iria acontecer anos mais tarde com o Museu Nacional) e temo que possa acontecer algo terrivel com esses desenhos caso fique (sic) com alguma dessas instituições.

- Mas João, tem gente qualificada e habilitada para fazer uma boa guarda desses trabalhos. Confie, dê um crédito para esse pessoal, insisti, na tentativa de demovê-lo desse pensamento.

- Não, Lin. O Rio está tão quebrado que prefiro dar esses desenhos pra você que é tão entusiasmado com essas coisas, do que para uma dessas instituições do Governo. Quer os desenhos para você? respondeu, com tranquilidade e segurança. 


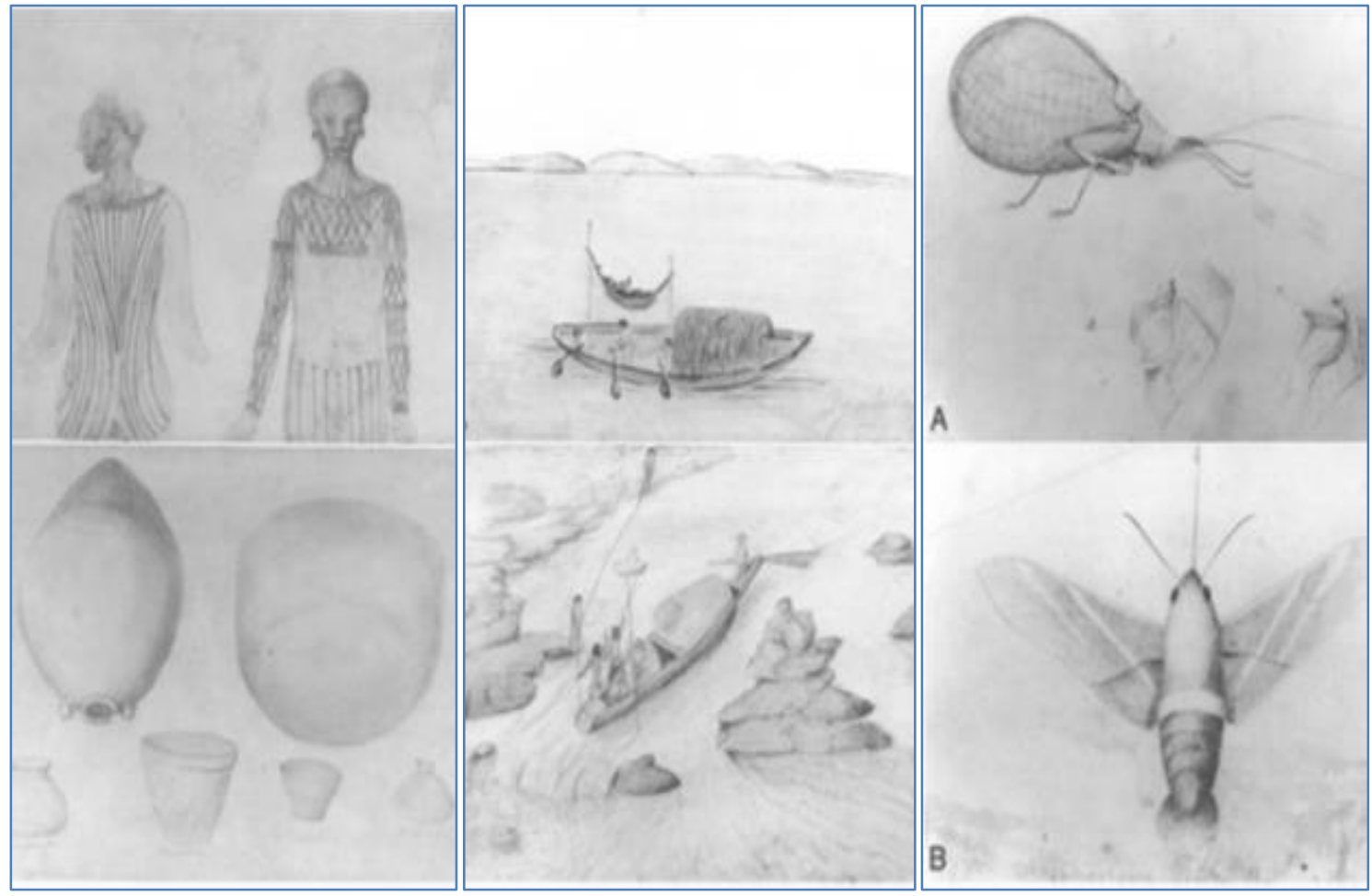

Figura 6. Fac-símiles das ilustrações do artigo publicado na revista Brittonia.

Fiquei extremamente surpreso com essa ideia do João. Afinal, não tinha interesse em ficar com esses desenhos, que são importantes e valiosos documentos históricos. Nem pensaria em vendê-los para algum colecionador - nem imagino o valor monetário dessas obras. Minha opinião continuava a mesma: esses desenhos tinham que estar guardados em uma instituição de pesquisa oficial brasileira.

João Paulo já estava preparando seu retorno ao Brasil. Nesses anos todos em que viveu nos Estados Unidos, continuou pagando o INSS com ajuda de seu irmão e garantiu uma aposentadoria brasileira, bem como outra pequena pelo lado americano. Assim, em pouco tempo iria preparar suas malas e voltar ao Rio, onde havia comprado uma modesta casa num município perto de Cabo Frio e por lá ficaria.

Resolvi rapidamente o dilema: decidi aceitar a doação das obras do Barbosa Rodrigues, pois, se o João Paulo levasse as obras para sua nova residência, poderiam estar mal acondicionadas e poderiam se deteriorar em pouco tempo, ou ainda se perderem na viagem, etc. Assim, naquele momento, ganhei dele os desenhos e me senti não como quem recebeu a doação das obras, mas de seu fiel depositário, uma vez que, com mais tempo, iria verificar qual instituição seria a destinatária final para a guarda desse material.

Preocupado que sou com esse procedimento, falei para ele que nós deveríamos assinar um termo de doação das obras para que, oficialmente, esse ato pudesse ser conhecido e validado, e não dar margens para outros possíveis entendimentos. João disse não ser necessário, valia a palavra apenas. De todo modo, tiramos fotos juntos com um dos desenhos à mostra nas mãos, registrando o momento. Pronto, penso que isso poderia ser usado como comprovante da doação e do recebimento.

Passado um tempo, tanto João quanto eu retornamos ao Brasil e cada um seguiu seu caminho. Acondicionei os desenhos, um a um, entre duas folhas de papel sulfite e os protegi dentro de uma pasta de cartolina grossa e a deixei em uma gaveta de minha escrivaninha na Faculdade em Botucatu (Figura 7). E a pasta ficou nessa condição por alguns anos, até que num certo ano, ao abrir a gaveta e notar a pasta, voltou a lembrança de que eu deveria encontrar uma instituição.

Como não tenho muita familiaridade com esse tema, resolvi consultar alguns especialistas, pessoas que tivessem boa experiência no trato de documentos históricos e também fossem conhecedoras dos procedimentos técnicos de conservação e guarda por instituições responsáveis. Após as consultas, foime sugerido que o local poderia ser a Biblioteca Nacional, que tem um setor de obras raras, e os desenhos poderiam ser assim considerados e receberiam a merecida atenção.

Decidido e feito, os desenhos teriam então um novo lar. Mas, levado pelo vai-e-vem das atividades acadêmicas na UNESP, acabei, de novo, me esquecendo da decisão, deixando os desenhos novamente na gaveta da escrivaninha de minha sala, que ficaram ainda mais esquecidos, uma vez que retornei 
novamente a Nova York para um estágio sênior no exterior, por um ano, desta vez no Jardim Botânico de Nova York, com plantas alimentícias utilizadas por comunidades indígenas do Alto Rio Negro, Amazonas. Lembrava dos desenhos quando encontrava alguma coleta botânica feita pelo Barbosa Rodrigues naquela região específica, durante minhas pesquisas de herbário.

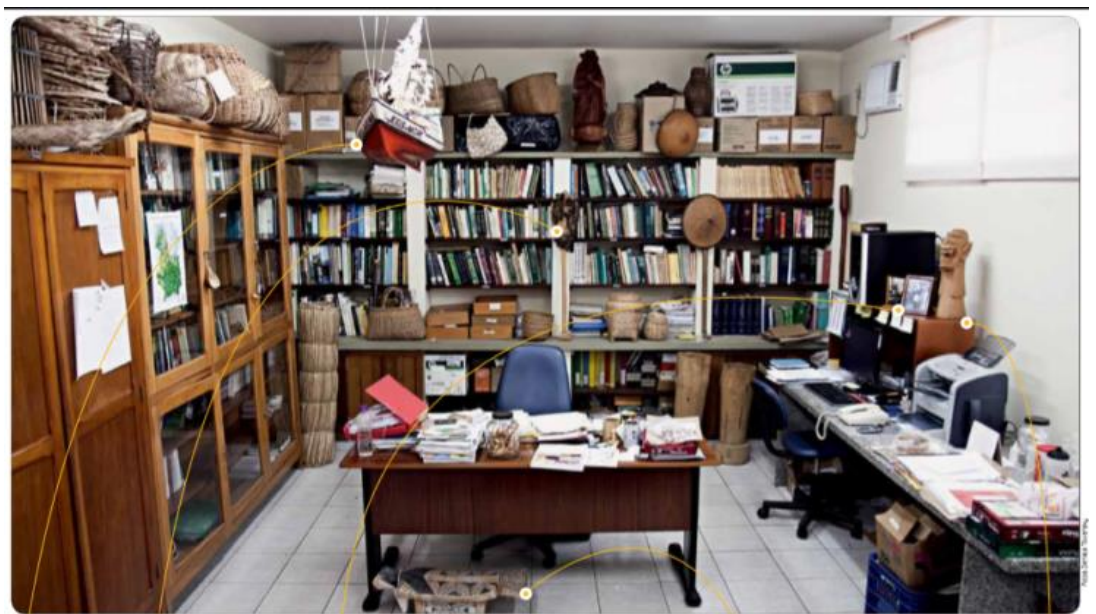

Figura 7. Sala do professor Lin Chau Ming na FCA - UNESP (fonte: Revista Unesp Ciência).

Retorno ao Brasil em julho de 2018 e logo em seguida vou a Belém participar do XII Simpósio Brasileiro de Etnobiologia e Etnoecologia e XV Congresso da Sociedade Internacional de Etnobioloiga (o Belém +30), e aproveitei a presença de muitos colegas etnobotânicos e consultei outras pessoas sobre o melhor encaminhamento a ser dado para os desenhos.

Decido mudar. Sugerido então por vários colegas, refleti e pensei que o melhor local para a guarda desse material seria na Biblioteca do Jardim Botânico do Rio de Janeiro, que se chama, igualmente, Biblioteca Barbosa Rodrigues e que também possui um periódico científico na área de Botânica chamado Rodriguésia, ambos em homenagem a quem foi seu diretor. Acho que tudo isso levava a apenas um local, a esse local, e então bati o martelo.

Acertei com a Viviane Stern da Fonseca-Kruel, do Jardim Botânico do Rio de Janeiro, que pouco tempo atrás havia organizado uma coleção etnobotânica em sua instituição e definimos a realização de um evento para a entrega oficial dos originais, sem data marcada, mas que seria em 2019, pois se comemorava o $110^{\circ}$ aniversário do Barbosa Rodrigues.

Em setembro de 2018 veio o horror do incêndio do Museu Nacional. Consideráveis acervos foram consumidos pelas chamas (Figura 8). Perdas irreparáveis para a Ciência brasileira. A parte botânica estava a salvo porque havia sido transferida do prédio alguns anos antes. As fagulhas atingiram meu pensamento sobre as obras que estavam em Botucatu. Fui procurá-las na gaveta. Continuavam lá.

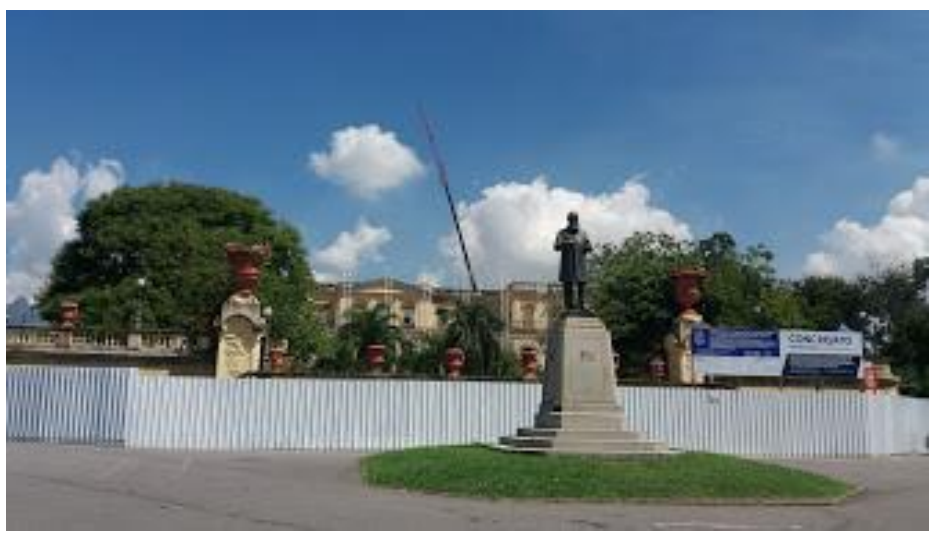

Figura 8. Museu Nacional em obras de restauração de seu prédio, em 2019.

Pressionado por mim mesmo diante dessa catástrofe e temendo acontecimento semelhante com os desenhos (impossível, pois a devastação do Museu Nacional não tem comparação!), decidi, definitivamente, encaminhar a doação. Não poderia mais postergar. Combinei com a Viviane e 
fechamos a data. Havia o bom argumento já citado, pois aquele ano representava os 110 anos da morte do botânico, então tudo foi feito para que fosse em 2019.

Viviane se apressou e organizou, com colegas de sua instituição, um evento chamado "Jardim Botânico celebra Barbosa Rodrigues", com uma programação que incluía a participação de outros pesquisadores com experiência nos estudos sobre o botânico, para o dia 27 de março de 2019.

$\mathrm{O}$ ato de recebimento da doação foi assinado pelo presidente do Jardim Botânico do Rio de Janeiro na época, Sérgio Besserman Vianna, ao final do evento, que contou com bom público e a biblioteca logo iria preparar uma exposição desses trabalhos que tinham acabado de ser incorporados ao seu acervo histórico (Figura 9). Meu compromisso estava então cumprido, finalmente. E os desenhos voltaram para o local de onde haviam saído.

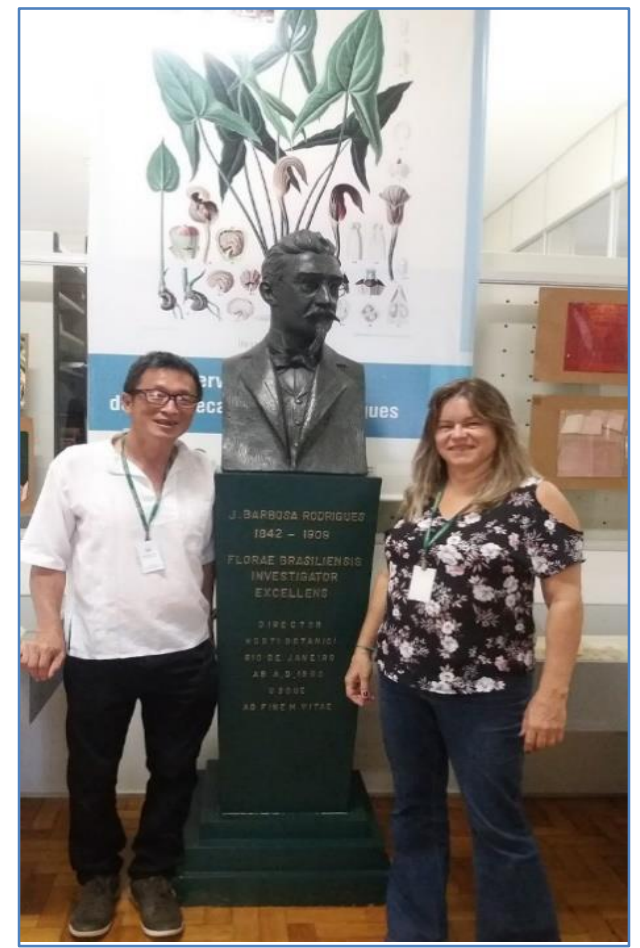

Figura 9. Professor Lin e sua esposa Margarete em frente ao busto de Barbosa Rodrigues na Biblioteca de mesmo nome no Jardim Botânico do Rio de Janeiro no dia da doação dos desenhos originais.

\section{Breve descrição das obras}

João Barbosa Rodrigues não era, em seu início acadêmico, um profissional com reconhecimento por outros cientistas da época. Era professor de desenho na Escola Pedro II e seus estudos botânicos eram considerados amadores. A situação mudou com a publicação de estudos taxonômicos de orquídeas, com desenhos detalhados, que começara a ganhar maior respeito por parte dos naturalistas, associado com o apoio que o Barão de Capenama e a Princesa Isabel lhe davam, garantindo recursos e suporte político, uma vez que estes participavam da elite política na época.

Era considerado um cientista extremamente ativo e trabalhador e se envolvia em diferentes áreas das Ciências, tendo produzido muitos trabalhos de Botânica, Etnografia, Antropologia, Linguística, Geologia e outras áreas. Foi casado três vezes e sua última esposa, Constança, também era uma boa desenhista, tendo colaborado com ele em vários trabalhos, incluindo os realizados durante o período em que esteve na Amazônia.

Conforme Mori e Castaño-Ferreira (1987), Barbosa Rodrigues esteve na Amazônia em diferentes períodos e provavelmente os originais apresentados neste trabalho se referem ao de 1873 a 1875 , pois num dos desenhos, o que retrata Silves, no Amazonas, é datado de 26 de julho de 1873.

Os desenhos, todos de tamanho $14 \mathrm{~cm} \times 20 \mathrm{~cm}$, foram numerados aleatoriamente, pois se encontravam separados na casa do tataraneto do Barbosa Rodrigues e caso houvesse alguma anotação ou desenho no verso, recebeu a letra "A" após o número do desenho. Os desenhos principais foram feitos a lápis e todos foram pintados com aquarela líquida e em alguns continham anotações manuscritas, de próprio punho. Como os desenhos foram colados sobre cartolina preta, em alguns dos versos dos 
desenhos encontravam-se ainda pedaços de fita crepe que os aderiam a essa cartolina. Uma das folhas encontrava-se parcialmente rasgada.

- Desenho 1a: Mostra um inseto, Orthoptera, da família Tettigoniidae, do grupo das esperanças, e detalhes de algumas articulações do inseto, em algum lugar do Amazonas.

- Desenho 1b: No verso deste desenho há outro mostrando uma canoa percorrendo trecho de um rio na Amazônia, com alguns morros na margem, ao fundo, e com indígenas remando, e uma pessoa, provavelmente Barbosa Rodrigues, deitado em uma rede dentro da canoa, que possui uma cobertura de palha. A perspectiva dessa rede não está adequadamente desenhada, parecendo estar parcialmente fora do barco. Há manuscritos a lápis em boa parte do desenho.
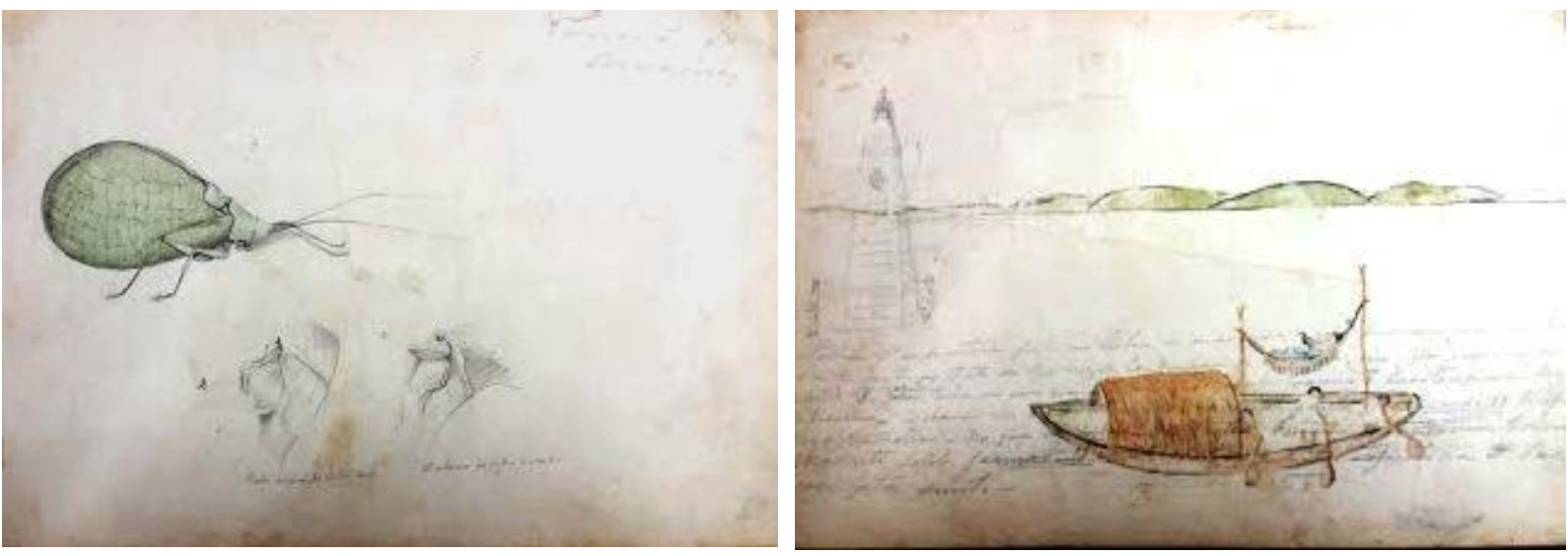

Esquerda: desenho 1a, direita: desenho $1 \mathrm{~b}$

- Desenho 2a: No desenho 2a é mostrada uma mariposa, da família Sphingidae, e alguns muiraquitãs, em vistas lateral, frontal e costal. Na parte de baixo, à direita, aparecem duas peças furadas, cuja finalidade não foi possível de ser verificada.

- Desenho 2b: No desenho 2b são mostrados rascunhos feitos a lápis em preto e branco, de um indígena e de um instrumento de sopro, provavelmente feito de cabaça (Lagenaria siceraria (Molina) Standl. - Cucurbitaceae ou Crescentia cujete L. - Bignoniaceae), com anotações manuscritas, e uma lança indígena que foi pintada com aquarela líquida, também com anotações manuscritas. Pode-se observar um pedaço de fita crepe usado para aderir o desenho à cartolina p reta.
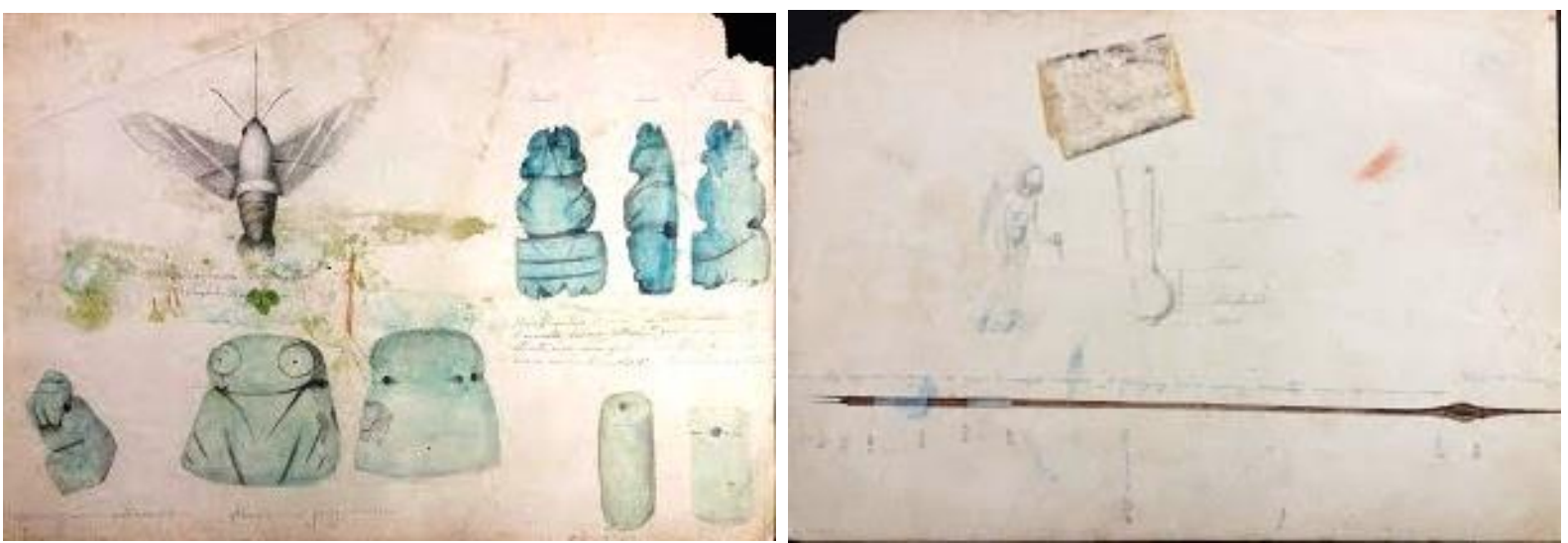

Esquerda: desenho 2a, direita: desenho $2 \mathrm{~b}$ 
- Desenho 3a: No desenho 3a é mostrado um indígena Munduruku com pintura corporal avermelhada feita de urucum (Bixa orellana L. - Bixaceae) e esboços a lápis de uma cesta e de uma perna com linhas da pintura corporal.

- Desenho 3b: No desenho 3b há um esboço dos morros do Frade e da Freira, localizados no Espírito Santo e anotações manuscritas. Desde 2007 estão enquadrados como Monumento Natural.

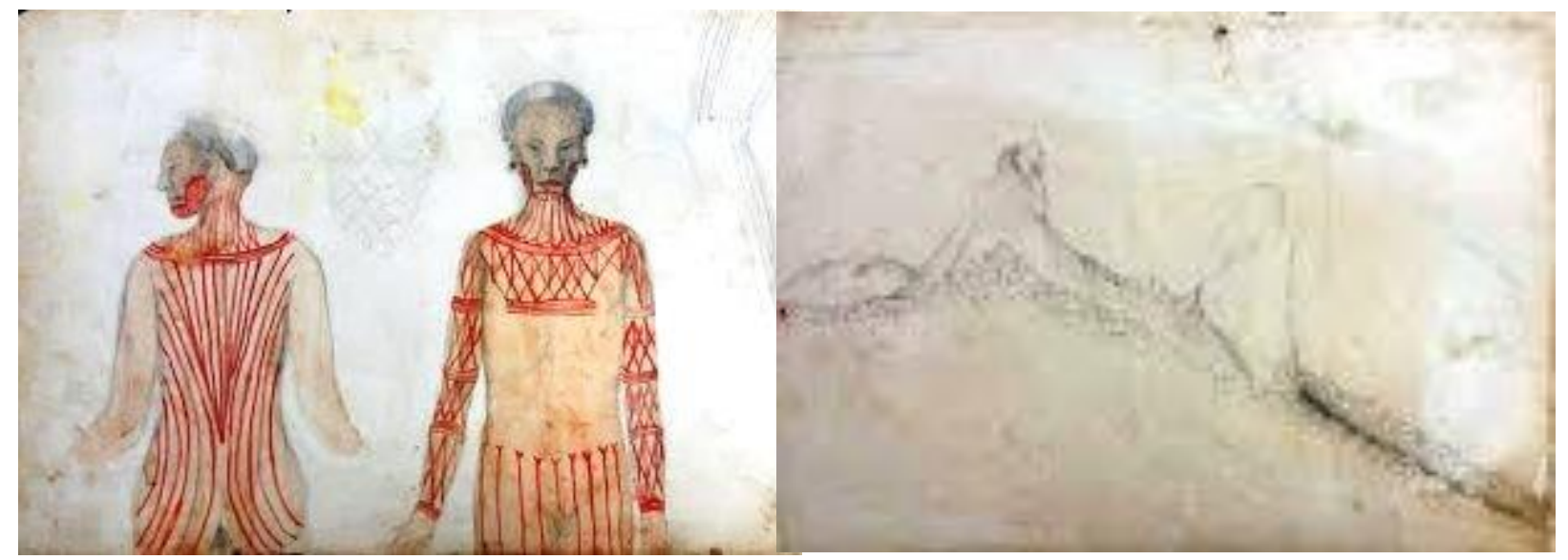

Esquerda: desenho 3a, direita: desenho 3b

- Desenho 4a: $\mathrm{O}$ desenho 4a mostra um barco indígena descendo uma corredeira de pedra, ajudado por indígenas com corda na margem do rio e a tripulação manobrando com vara e leme. Não há observação sobre sua localização e nem data.

- Desenho 4b: No desenho 4b é mostrada a impressão da lança indígena do desenho 2b, o que indica que houve sobreposição desta página naquele desenho. É possível ver também alguns rabiscos a lápis, a caneta nanquim e manchas de tinta azul, além do pedaço de fita crepe.

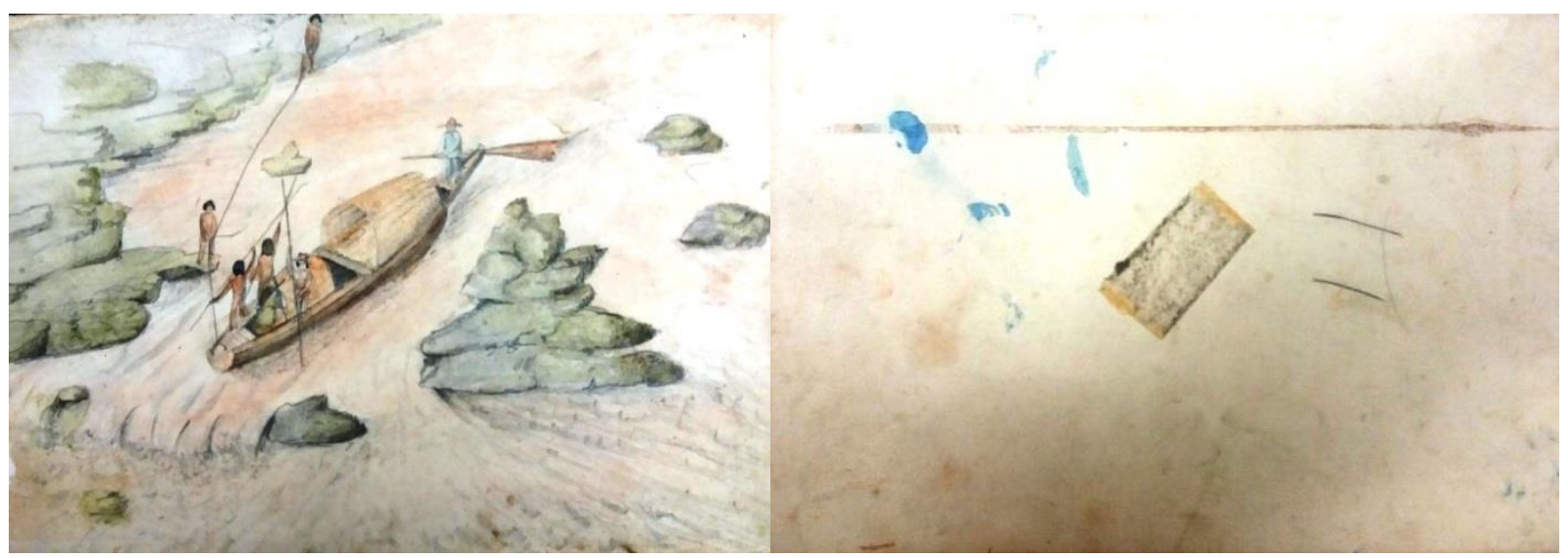

Esquerda: desenho 4a, direita: desenho $4 \mathrm{~b}$ 
- Desenho 5a: O desenho 5a mostra um cesto indígena para balançar crianças (macuru) e anotações manuscritas. Há ainda manchas coloridas de tinta e um desenho colorido não identificado.

- Desenho 5b: No desenho 5b é possível observar esboços diversos feitos a nanquim e manchas coloridas.
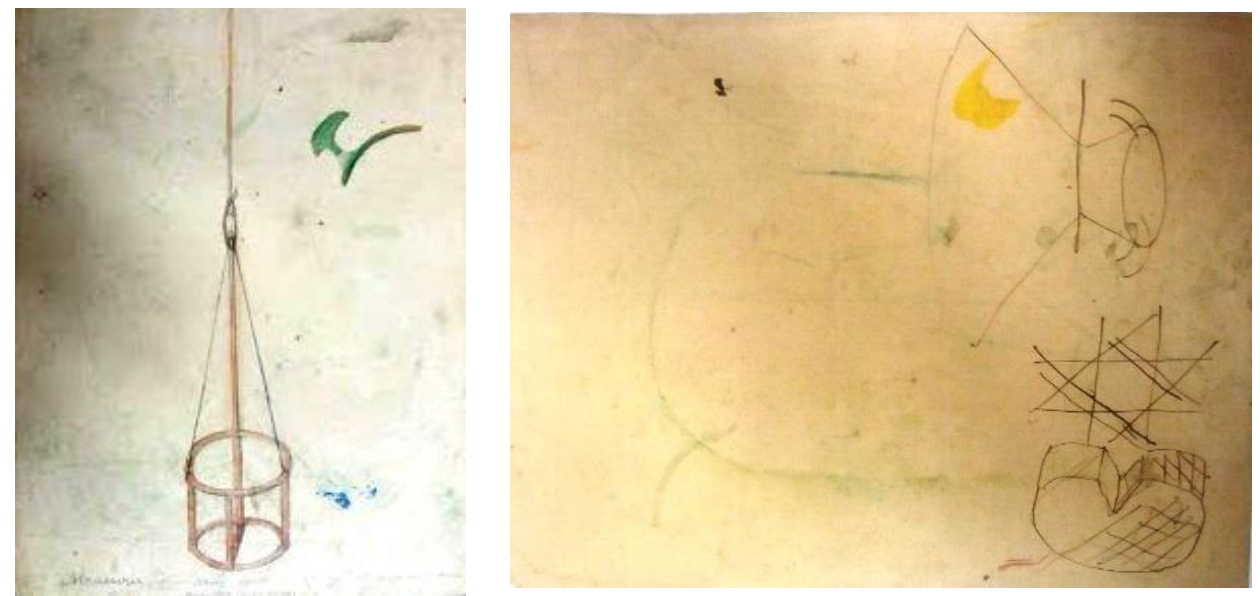

Esquerda: desenho 5a, direita: desenho 5b

- Desenho 6: No desenho 6 está representada uma vista de Silves, hoje município amazonense, e é o único datado $(26 / 07 / 1873)$.

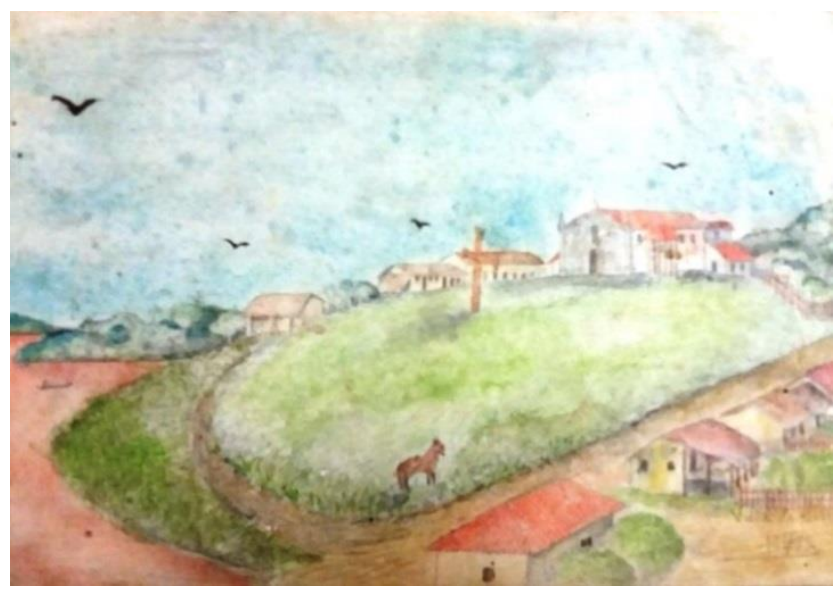

- Desenho 7: Desenho 7 mostra alguns modelos de machadinhos de pedra indígenas, com anotações manuscritas.

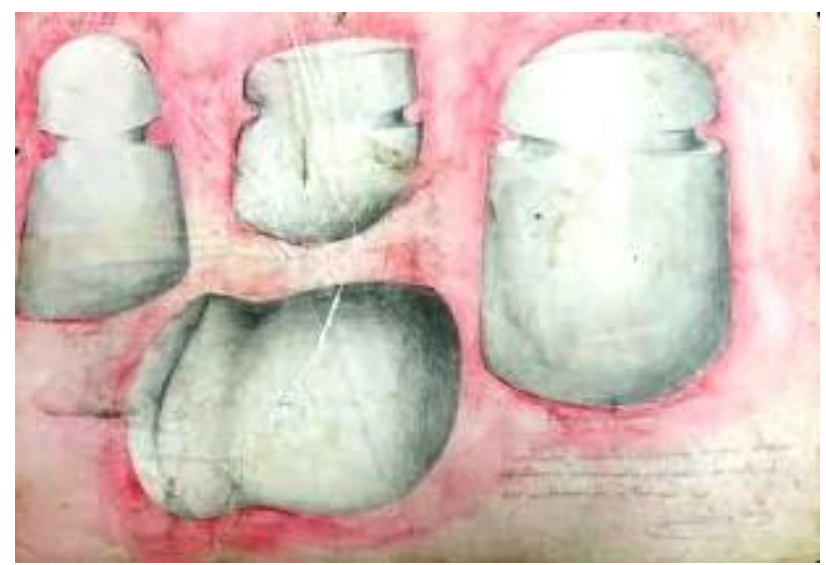


- Desenho 8: O desenho 8 mostra estudo de um machado de pedra, em suas faces frontal, lateral e pela parte de baixo e anotações manuscritas.

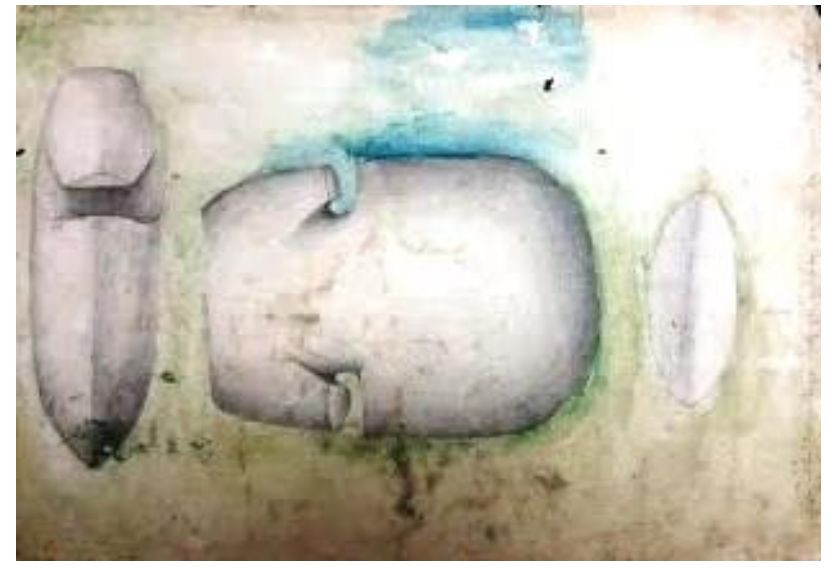

- Desenho 9: O desenho 9 mostra diversos tipos de utensílios cerâmicos, em tamanhos diferentes, como pote de armazenar água e vasos.

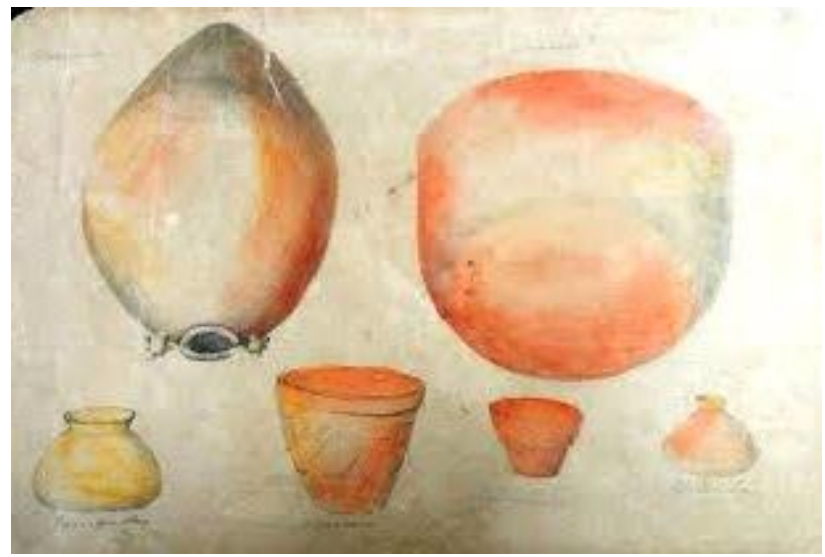

\section{CONSIDERAÇÕES GERAIS}

Os desenhos de Barbosa Rodrigues na Amazônia (ou parte deles) estão devidamente doados e conservados na Biblioteca do Jardim Botânico do Rio de Janeiro, constituindo-se em importante material histórico para o estudo sobre a produção científica e artística desse grande botânico brasileiro. $\mathrm{O}$ caminho que eles tomaram para chegar a isso reuniu coincidências que envolveram elementos pessoais e familiares do autor desse artigo e de situações acadêmicas em Nova York, seguido por envolvimento com instituições de pesquisa no Brasil.

Como é possível verificar, são desenhos separados, de diferentes assuntos, biológicos, minerais e culturais, todos provavelmente realizados na Amazônia (exceção: Morros do Frade e da Freira, no Espírito Santo). Mostram aspectos de sua viagem (barco no rio e na corredeira) e de alguns momentos do cotidiano indígena (pintura corporal) e seus utensílios (muiraquitãs, machados de pedra, vasos e potes cerâmicos, lança e cesto para balançar crianças). Insetos são retratados também, assim como paisagens (Silves e Morros do Frade e da Freira), mostrando a abrangência nos interesses e estudos realizados por ele, que incluíam, dentre outros, Arqueologia, Botânica, Etnografia, Geologia e Zoologia.

As anotações manuscritas pelo botânico também revelam algumas dessas características, porém é necessário um estudo mais pormenorizado para que se entenda seu contexto e significado histórico. Sabe-se que sua viagem para a Amazônia foi realizada com preparo antecedente, com equipamentos para coleta botânica e materiais de desenho, apoiada pela sua terceira esposa, Constança Pace, que também o ajudava nos desenhos botânicos (e provavelmente de outros assuntos).

Seu tataraneto, João Paulo, falou que sua mãe era uma ótima desenhista e que vez ou outra a via manuseando os desenhos de Barbosa Rodrigues, nuns "caderninhos" dele, conforme ele relatou. E disse que viu alguns deles sendo pintados pela mãe, ou seja, é possível que alguns dos desenhos em aquarela 
não tenham sido pintados por ele, e sim, pela sua bisneta, cem anos depois de sua elaboração. Mas os desenhos não estavam agrupados na forma de uns cadernos, estavam soltos, individualizados, expostos nas paredes do apartamento em Nova York. Não foram encontrados outros desenhos do botânico para ter maiores referências.

Algumas evidências nos desenhos podem ser verificadas para confirmar essa informação, como alguns rabiscos feitos a nanquim (que parecem ter traços uniformes, o que não é característico de bico de pena e sim, com caneta de nanquim para desenho técnico, mais atual), diferentes do restante dos outros desenhos, feitos a lápis. Há também desenhos que parecem ter sido pintados com lápis de cor e outros com aquarela líquida.

Apesar da dificuldade, seria interessante fazer o rastreamento de onde poderiam estar outros trabalhos de Barbosa Rodrigues, com algum de seus descendentes ainda vivos, para se ter mais materiais para análise.

Somente com estudos mais acurados será possível verificar se realmente foi ele quem pintou os desenhos, o que será trabalho de pesquisa para outros profissionais, mas a informação dada por seu tataraneto é o início dessa dúvida.

\section{AGRADECIMENTOS}

O autor agradece a Viviane Stern Fonseca-Kruel, do Jardim Botânico do Rio de Janeiro, pela inestimável articulação para a viabilização do evento de doação dos desenhos; a Maria Franco Trindade Medeiros, do Museu Nacional, por orientação quanto à conservação de desenhos históricos; aos entomólogos Eraldo Costa Neto, da Universidade Estadual de Feira de Santana, e João Pedro de Andrade Bomfim, da UNESP-Botucatu, pelas identificações dos insetos a partir dos desenhos. Gostaria também de agradecer a João Paulo Castaño-Ferreira, pela gentil doação dos desenhos e pela confiança a mim depositada, sem os quais estes não teriam retornado ao Jardim Botânico do Rio de Janeiro.

\section{REFERÊNCIAS}

Cinemateca Brasileira. Disponível em: <http://bases.cinemateca.gov.br/cgibin/wxis.exe/iah/?IsisScript=iah/iah. $x$ is\&base=FILMOGRAFIA\&lang=p\&nextAction=lnk\&exprSearch=ID=02 5843\&format=detailed.pft $>$. Acessado em: 16 mar 2020.

Ferreira, L.M.; Noelli, F.S. João Barbosa Rodrigues precursor da etnoclassificação na arqueologia amazônica.

Amazônica - Revista de Antropologia, Goiânia, v. 1, n. 1, p. 68-95, 2009.

Guerra, G.A.D. Imagens do estatuário da Igreja de Nossa Senhora de Pompéia, em Manhattan, Nova York, nos

Estados Unidos da América. Fragmentos de Cultura, Belém, v. 21, n. 2, p. 329-359, 2011.

Ihering, H.V. João Barbosa Rodrigues. Revista do Museu Paulista, São Paulo, Typographia do Diário Oficial, v. 8, p. 23-37, 1911.

Instituto de Pesquisas. Jardim Botânico do Rio de Janeiro. Disponível em <https://aplicacoes.jbrj.gov.br/materias/21_10_2009.html>. Acessado em: 17 mar 2020.

Mori, S.A.; Castaño-Ferreira, F. A distinguished Brazilian botanist, João Barbosa Rodrigues (1842-1909),

Brittonia, v. 39, n. 1, p. 73-85, 1987.

Our Lady of Pompeii Church. Disponível em: <https://olpnyc.org/ >. Acessado em: 17 mar 2020.

Peixoto, A.L.; Guedes-Bruni, R.R.; Haverroth, M.; Silva, J.M. Saberes e práticas sobre plantas: a contribuição

de Barbosa Rodrigues. Revista Brasileira de História da Ciência, Rio de Janeiro, v. 5(supl.), p. 22-30, 2012.

Porto, J.C. Histórico do Museu Botânico do Amazonas. Vellosia, Rio de Janeiro, v. 1, p.61-80, 1891.

Rodrigues, J.B. Exploração e estudo do Valle do Amazonas. Rio de Janeiro: Typhographia Nacional, 1875, $52 \mathrm{p}$.

Rodrigues, J.B. Genera et species orchidearum novarum quas sollegit, descripsit et iconibus illustravit.

Rio de Janeiro: Imprimerie de C. et H. Fleiuss, 1877, 77p.

Rodrigues, J.B. Hortus fluminensis, ou breves notas sobre as plantas cultivadas no Jardim Botânnico do

Rio de Janeiro para servir de guia aos visitantes. Rio de janeiro: Typh. De G. Leuzinger \& Filhos, 1893, 457p. Rodrigues, J.B. Hortus fluminensis. Revista do Serviço Público, v. 111, n. 4, p. 209-224, 1983.

Rodrigues, J.B. Ídolo amazônico, achado no rio Amazonas. Rio de Janeiro: Typhographia Nacional, 1875, $17 \mathrm{p}$.

Rodrigues, J.B. Poranduba amazonense, ou kochiyma-uara porandub 1872-1882. Rio de Janeiro: Typh.

De G. Leuzinger \& Filhos, 1890.

Rodrigues, J.B. Sertum Palmarum Brasiliensium: relation des palmiers nouveaux du Brésil. 2 vol. Bruxeles:

Imprimerie Veuve Monnom, 1903.

Sá, M.R. O botânico e o mecenas: João Barbosa Rodrigues e a ciência no Brasil na segunda metade do século

XIX. História, Ciência, Saúde - Manguinhos, Rio de Janeiro, v. 8(Supl.), p. 899-924, 2001. 